\title{
La gestión estratégica en tiempos de Covid-19: una mirada desde el sector turístico - subsector de alojamiento
}

\author{
Jonathan Alexis Restrepo Montes* \\ Flor Ángela Marulanda Valencia** \\ Diego Germán Arango Muñoz***
}

Fecha de recibido: 12 de marzo de 2021

Fecha de aprobado: 8 de octubre de 2021

Para citar este artículo: Restrepo Montes, J. A., Marulanda Valencia, F. A., \& Arango Muñoz, D. G. (2021). La gestión estratégica en tiempos de Covid-19: una mirada desde el sector turístico - subsector de alojamiento. Revista Universidad \& Empresa, 23(41), 1-34. https://doi.org/10.12804/revistas.urosario.edu.co/empresa/a.10376

\section{Resumen}

Este estudio tuvo como objetivo aplicar algunos de los planteamientos teóricos de la gestión estratégica al análisis de las medidas tomadas en establecimientos del subsector de alojamiento en Medellín ante el

* Magíster en Ingeniería Administrativa, Universidad Nacional de Colombia; especialista en Gestión Empresarial, Universidad Nacional de Colombia; Administrador de Empresas Turísticas, Institución Universitaria Colegio Mayor de Antioquia (Medellín, Colombia). Correo electrónico: joarestrepomo@unal.edu.co. ORCID: https://orcid.org/0000-0003-1852-813X

** Doctora en Ingeniería, Industria y Organizaciones, Universidad Nacional de Colombia; magíster en Ciencias de la Administración, Universidad EAFIT; Ingeniera Administradora, Universidad Nacional de Colombia. Profesora asociada del Departamento de Ingeniería de la Organización, Facultad de Minas, Universidad Nacional de Colombia - sede Medellín. Correo electrónico: famarulan@unal.edu.co ORCID: https://orcid.org/0000-0003-2036-0639

*** Especialista en Gerencia Deportiva, Universidad Autónoma Latinoamericana (Colombia); Ingeniero Administrador, Universidad Nacional de Colombia. Instructor asociado del Departamento de Ingeniería de la Organización, Facultad de Minas, Universidad Nacional de Colombia - sede Medellín. Correo electrónico: dgarango@unal.edu.co ORCID: https:// orcid.org/0000-0002-1429-9029 
La gestión estratégica en tiempos de Covid-19: una mirada desde el sector turístico - subsector de alojamiento

confinamiento y cierre de fronteras decretados para contener la pandemia del Covid-19. La información recolectada a partir de entrevistas con el personal directivo de establecimientos de alojamiento, el análisis de contenido de información publicada por entidades especializadas y la revisión de prensa permitieron realizar un diagnóstico de estos establecimientos en el momento más crítico, identificar estrategias de supervivencia y futuras perspectivas. Como resultado, los hoteles han disminuido drásticamente sus ingresos, lo que les ha dificultado el pago de sus gastos operacionales y obligaciones financieras. Sus directivos han tomado decisiones de reducción de costos que impactaron a sus stakeholders, y algunos establecimientos se adaptaron a los cambios del entorno a través de la modificación en los protocolos internos de prestación del servicio. Muchos establecimientos medianos y pequeños han cerrado operaciones, los formatos menos afectados han sido los que ofrecen largas estadías y algunas medidas gubernamentales han logrado mitigar los efectos negativos. El miedo o los deseos de vivir intensamente serán los sentimientos pospandemia en la población, que pueden salvar o acentuar la crisis.

Palabras clave: estrategias; crisis; turismo; hotelería; Covid-19.

\title{
Strategic Management in Times of Covid-19: A Look from the Tourism Sector - Accommodation Subsector
}

\begin{abstract}
This study aimed to apply some of the theoretical approaches of strategic management to the analysis of the measures taken in the accommodation establishments subsector of Medellin in view of the confinement and closure of borders to contain the Covid-19 pandemic. The information collected from interviews with the management staff of accommodation establishments and the content analysis of information published by specialized entities and the press review allowed a diagnosis of these establishments at the most critical moment, identifying survival strategies and future perspectives. As a result, hotels have drastically decreased their revenues, making it difficult for them to pay their operational expenses and financial obligations. Its managers have made cost reduction decisions that impacted their stakeholders, and some establishments have adapted to changes in the environment by modifying internal protocols for service provision. Many medium and small establishments have closed operations, the least affected formats have been those that offer long stays, and some government measures have managed to mitigate the negative effects. The fear or the desire to live intensely will be the post-pandemic feelings in the population, which can save or accentuate the crisis.
\end{abstract}

Keywords: Strategies; crisis; tourism; hospitality; Covid-19.

\section{Gestão estratégica em tempos de Covid-19: um olhar do setor de turismo - subsetor de hospedagem}

\section{Resumo}

O presente estudo teve como objetivo aplicar algumas das abordagens teóricas da gestão estratégica, à análise das medidas tomadas nos estabelecimentos do subsetor de alojamento de Medellín, face ao confinamento e fechamento de fronteiras decretado para conter a pandemia do Covid-19. A informação recolhida a partir de entrevistas com gestores de estabelecimentos de alojamento, da análise de conteúdo de informação publicada por entidades especializadas e da crítica de imprensa, permitiu um diagnóstico destes estabelecimentos no momento mais crítico, identificando estratégias de sobrevivência e perspectivas futuras. Como resultado, os hotéis reduziram drasticamente suas receitas, dificultando o pagamento de suas despesas operacionais e obrigações financeiras. Seus gestores tomaram decisões de redução de custos que impactaram seus stakeholders, e alguns estabelecimentos se adaptaram às mudanças no ambiente, modificando protocolos internos de prestação de serviços. Muitos estabelecimentos de médio e pequeno porte interromperam suas atividades, os formatos menos afetados são os que oferecem estadias longas e algumas medidas governamentais têm conseguido mitigar os efeitos negativos. 
O medo ou a vontade de viver intensamente serão os sentimentos pós-pandêmicos na população, que poderam salvar ou acentuar a crise.

Palavras-chave: estratégias; crise; turismo; hotelaria; Covid-19.

\section{Introducción}

En una situación como la que se vive a nivel mundial debido a la pandemia del Covid-19, toma especial validez el planteamiento de Kotler y Caslione (2009) en cuanto que la extrema incertidumbre es la nueva normalidad para las organizaciones, esto se da especialmente para los negocios que pertenecen a sectores considerados como no esenciales para garantizar la vida.

Uno de los sectores que más se ha visto afectado por las medidas preventivas que se tomaron en todos los países es el turismo, que se había constituido en un importante dinamizador de la economía a nivel global, al mantener unas tasas de crecimiento notables, principalmente desde la Segunda Guerra Mundial (Jafari, 2005). Constantemente surgían nuevos destinos con ofertas para todo tipo de públicos, causando, además, impactos, tanto positivos como negativos, a nivel económico, sociocultural y medioambiental en los lugares de llegada (Gil \& Korstanje, 2020). Se afirma que, incluso, este sector puede contribuir de forma directa o indirecta al cumplimiento de los Objetivos de Desarrollo Sostenible. Específicamente se ha incluido en algunas de las metas de los objetivos 8, 12 y 14: "trabajo decente y crecimiento económico", "producción y consumo responsables" y "vida submarina"; esto desde el punto de vista del turismo sostenible (омт, 2020a, p. 1). De acuerdo con este organismo, el turismo internacional había tenido un crecimiento continuo durante los últimos diez años, alcanzando una cifra de 1500 millones de turistas en 2019. Las exportaciones por este concepto crecieron más rápido que las exportaciones de mercancías, al lograr un total a nivel global de usD 1.7 billones en 2018. Además, 1 de cada 10 empleos en el mundo se generaban en este sector (омт, 2019).

En el contexto colombiano, el turismo también ha sido una de las apuestas lideradas desde el gobierno nacional, a través de distintas políticas y planes sectoriales, que lo conciben como una "locomotora de desarrollo", pues durante el año 2019 la contribución del turismo 
al valor agregado nacional fue del $2.15 \%$, y, para el subsector de servicios de alojamiento y alimentación, dicho valor creció al $4.7 \%$ respecto a 2018, llegando a los cop 34.1 billones. Las divisas por concepto de viajes y transporte aéreo de pasajeros crecieron un $2.4 \%$, sumando usD 6786 millones, y el número de visitantes no residentes aumentó un 3\%, alcanzando una cifra récord de 4528912. Adicionalmente, el turismo generó 618000 trabajos de tiempo completo, equivalente al 3\% del total de ocupados en el país (Ministerio de Comercio, Industria y Turismo, 2020b, p. 12).

No obstante, ninguna entidad del sector público o privado a nivel mundial estaba preparada para la crisis derivada del Covid-19, la cual cambiaría drásticamente el panorama del sector viajes y turismo debido al cierre de fronteras globales, aislamiento social y la cancelación masiva de eventos. Esto ha generado afectaciones sin precedentes al empleo y los ingresos de las personas que dependen directa o indirectamente de esta actividad económica.

Analistas como Gössling, Scott y Hall (2020) afirman que los países de bajos ingresos serán los más afectados por la crisis, pues la administración de finanzas personales tiene una incidencia directa en la toma de decisiones de consumo, dentro de las cuales el presupuesto para gastos por concepto de viajes y turismo se suele clasificar en la categoría de suntuosos. Situación similar puede presentarse a nivel organizacional, en el que los desplazamientos por concepto de negocios serán reemplazados, en gran medida, por el contacto remoto a través de videoconferencias.

Particularmente, el subsector de alojamiento presenta una situación compleja, pues, debido al aislamiento, la mayoría de las reservas de los clientes fueron canceladas. Algunas de las grandes cadenas aún están operando, pero muchas de las propiedades más pequeñas han cerrado sus puertas (Jain, 2020). Lo que los hace más vulnerables es que los hoteles tienen costos fijos elevados, por ende, son sensibles a las condiciones de la economía, ya que, en períodos de crisis, estos no pueden reducir parte importante de sus costos (Alberca \& Parte, 2013).

Este estudio tuvo como objetivo aplicar algunos de los planteamientos teóricos de la gestión estratégica al análisis de las medidas implementadas por los directivos de establecimientos del subsector de alojamiento de la ciudad de Medellín (capital del departamento de Antioquia, en Colombia) en relación con el manejo de la crisis durante la cuarentena 
obligatoria decretada por el gobierno nacional. Para ello, se revisaron portales de agremiaciones y plataformas especializadas, prensa y literatura asociada. Finalmente, se entrevistaron directivos de varios establecimientos dedicados a esta actividad, en los que se incluyeron tres cadenas de gran formato, un hotel mediano y la agremiación de pymes del turismo, que, entre otros operadores de la cadena de valor de este sector, agrupa y representa a los pequeños prestadores de servicio de hospedaje.

El artículo inicia con la revisión de literatura en la que se presentan planteamientos sobre la gestión estratégica en tiempos de crisis y turbulencia, para luego describir aspectos teóricos y empíricos del sector turístico y el subsector de alojamiento en la situación actual de pandemia. Luego, se explica la metodología utilizada en el estudio, para dar paso a los resultados, que se exponen en cinco apartados: diagnóstico, medidas adoptadas por los entes gubernamentales y gremiales, estrategias de supervivencia, alternativas y perspectivas. Dentro de cada uno, se hace un análisis que parte de la situación mundial o nacional, pasando por lo gremial, hasta llegar al caso particular de los establecimientos hoteleros representados por los entrevistados.

\section{Revisión de literatura}

\subsection{La gestión estratégica en tiempos de crisis}

De acuerdo con Nag, Hambrick y Chen (2007), "el campo de la gestión estratégica se ocupa de las principales iniciativas previstas y emergentes tomadas por los directores generales en nombre de propietarios, que implican la utilización de recursos para mejorar el desempeño de las empresas en sus entornos externos" (p. 942). Entornos que generalmente presentan mucha incertidumbre, derivada, entre otros, de la tecnología, de la globalización y de las transformaciones culturales, que llevan a que los planes estratégicos más cuidadosamente elaborados sean inutilizados por estos cambios rápidos e imprevistos (Hill \& Jones, 2009). En forma complementaria, se habla de contingencia empresarial, clasificada en dos categorías: contingencias organizacionales y contingencias del entorno; las primeras abarcan aspectos internos como el tamaño de la empresa, su trayectoria, desarrollo humano e 
intensidad de capital. Las del entorno están relacionadas con la complejidad y hostilidad del mercado, que obligan a que los procesos de planeación estratégica sean más integrales y sofisticados con el fin de adaptarse a esas condiciones poco controlables (Wolf \& Floyd, 2013). Es así que la responsabilidad del director es crear una posición estratégica que asegure la viabilidad futura de la organización (Ansoff et al., 2018).

Para brindar un marco que permita a los directores enfrentar estos retos, se han desarrollado diferentes enfoques en relación con la gestión estratégica, ejemplos de ellos son: el basado en los recursos, los costos de agencia, la calidad total y de los stakeholders o grupos de interés. Este último, al considerar tanto el nivel interno como externo de la organización, tiene cada vez mayor aceptación. Este enfoque se basa en la premisa de que los gerentes deben administrar e integrar las relaciones e intereses de accionistas, empleados, clientes, proveedores, comunidades y otros grupos de una manera que garantice el éxito a largo plazo. Un enfoque de partes interesadas enfatiza la gestión activa del entorno empresarial, las relaciones y la promoción de intereses compartidos (Freeman \& McVea, 2001). En este sentido, Lynch (2018) hace referencia al poder otorgado a los altos funcionarios para dirigir los asuntos organizacionales, quienes actúan como agentes en nombre de las partes interesadas de la compañía, las cuales deben beneficiarse de una u otra forma del valor generado por los activos de la organización.

Pero más allá de los desafíos que impone el mundo cambiante dentro de una dinámica de globalización, progresos tecnológicos y la atención a las necesidades de los stakebolders, se encuentran los acontecimientos de gran impacto que son difíciles, por no decir imposibles, de prever. En este sentido, se habla de desastres y crisis. Los académicos afirman que son diferentes los desastres naturales (como los huracanes) y sociotécnicos (como accidentes aéreos) de las crisis comerciales por dos razones: los desastres pueden ser eventos naturales o provocados por el hombre, o ambos, mientras que las crisis comerciales son únicamente eventos provocados por el hombre. En segundo lugar, los desastres implican amenazas de lesiones y pérdida de vidas humanas, mientras que las crisis comerciales dañan la calidad de la vida personal, social y laboral de las personas (Wang, 2009). Para algunos académicos como Karam (2018), en escenarios críticos, es importante integrar la gestión de crisis con la planeación estratégica para su manejo de forma eficaz. La gestión de crisis tiende a centrarse en las amenazas de un entorno volátil y la capacidad de la empresa para sobrevivir, mientras que la planeación estratégica se concentra en las 
oportunidades inherentes al cambio y en la capacidad de las compañías de prosperar; sin embargo, ambas tienen una relación estrecha al ocuparse del futuro de la organización a través de la planificación y adaptación de dimensiones como el liderazgo, la cultura y la toma de decisiones.

En general, las situaciones imprevistas obligan a las organizaciones a comprender las dinámicas y transformaciones del entorno con el fin de diseñar estrategias para su manejo, lo que requiere de la capacidad de ajustarse al nuevo contexto a través de cambios y mejoras (Azócar, 2017). Otros autores hablan en términos más genéricos de turbulencia como un fenómeno impredecible que se relaciona con el aumento del riesgo y la incertidumbre. Se puede generar cuando coinciden elementos como: acontecimientos disruptivos, incremento de rivalidad con los competidores, disminución en la certitud para la toma de decisiones y dificultad en la relación con los stakebolders (Rivera, 2019). De este modo, anticipar el futuro se vuelve difícil, lo que obliga a las compañías a adaptarse en tiempo real a eventos inesperados, por medio de un enfoque de resiliencia (Ansell, 2017). Al respecto, Duque (2014) sostiene que los cambios organizacionales son una condición crítica de supervivencia a nivel competitivo, pues las crisis y la turbulencia pueden aparecer en cualquier tiempo, en cualquier forma y en cualquier lugar, creando varios grados de perturbación para los negocios; además, algunas turbulencias serán completamente indetectables o se podrán detectar solo después de que el caos ha llegado (Kotler \& Caslione, 2009).

Se ha realizado gran cantidad de estudios empíricos para explicar las estrategias que diseñan los directivos con el fin de enfrentar la turbulencia y el caos. Así, para autores como De Villa y Rajwani (2013), la respuesta estratégica para enfrentar la crisis en las organizaciones está muy influenciada por la percepción de sus gerentes, la cual se forma por su esquema cognitivo, las creencias personales y las interacciones sociales. Según los autores, esas percepciones afectan la elección de las respuestas estratégicas que determinan el camino que seguirá la organización. Otros autores describen medidas más puntuales que buscan garantizar la supervivencia de la organización, como la reducción masiva de costos, la generación de efectivo, el aumento de la supervisión de los empleados y el estricto control presupuestario (Bourletidis \& Triantafyllopoulos, 2014). Pero también hay que considerar acciones estratégicas más drásticas, como liquidación de sociedades, creación de nuevas estructuras societarias, regularización, modernización, fusión, diversificación, 
reestructuración y reingeniería. El reajuste, la reducción de personal y la quiebra se identifican como algunos de los métodos tácticos apropiados de gestión de crisis (Groh, 2014).

Sin embargo, dada las magnitudes de las afectaciones actuales y la incertidumbre generada por la pandemia del Covid-19 en sí misma, todos los planteamientos teóricos se quedan cortos para guiar a los directores en una situación sin precedentes en la historia reciente mundial.

\subsection{Marco contextual: el turismo y el subsector de alojamiento}

Conceptualmente son múltiples y variadas las interpretaciones sobre el turismo, se trata de un fenómeno complejo, que ha sido definido parcialmente por distintas teorías y corrientes del pensamiento desde lo económico, cinético, psicosocial, legal, administrativo y geográfico, entre otros; además, comprende una amplia gama de servicios, dentro de los que se incluye el alojamiento. La Organización Mundial del Turismo (омт) lo define como "un fenómeno social, cultural y económico que supone el desplazamiento de personas a países o lugares fuera de su entorno habitual por motivos personales, profesionales o de negocios" (омт, 2020b, p. 1); en forma similar, Catalano (2019) dice que la movilidad se considera como un elemento constitutivo de lo social, y, a su vez, el turismo se cataloga como un fenómeno en donde los traslados son inherentes a su definición. Para el autor, este sector es fundamental en el desarrollo de las sociedades, por ser una importante actividad económica asociada a la industria de los servicios.

Así como el turismo impacta a la sociedad, también se ve afectado por el contexto particular de la región en la que se desarrolla. El caso colombiano es una evidencia de esta situación, pues la actividad turística en el país presentó una fuerte disminución, por el recrudecimiento de la violencia, desde 1990. En 2005 este escenario empezó a mejorar, pero el verdadero crecimiento de este sector se ha presentado después del Acuerdo de Paz con la guerrilla de las FARC en 2016 (Menchero, 2018), y se ha convertido en una atractiva opción de negocios. Además, desde la institucionalidad se diseñan políticas públicas para estimular su crecimiento y generar un entorno favorable para la inversión, lo que ha permitido un aumento en los ingresos por concepto de viajes y turismo en la balanza de pagos (Benavides, 2015). Conforme con el Plan Sectorial de Turismo 2018-2022, que define la hoja de ruta y actuación del sector, este es uno de los países con mayor dinamismo en desarrollo turístico 
a nivel latinoamericano, razón por la cual se traza el objetivo de mejorar su competitividad como destino turístico, a través del fortalecimiento de la productividad, la generación de valor, el posicionamiento en los mercados, entre otros (Mincit, 2021).

De acuerdo con el "Reporte de competitividad de viajes y turismo 2019" del Foro Económico Mundial (WEF, por su sigla en inglés), que mide un conjunto de factores y políticas de un universo de 140 naciones, con el fin de determinar su nivel de desarrollo y competitividad en función de la sostenibilidad del sector turístico, Colombia ocupa el lugar número 55, lo que representa una evolución positiva para el país, ya que en 2015 se ubicó en el puesto 68 y en 2017, en el 62. El país se destaca en el subíndice de recursos naturales y culturales, y en la competitividad de precios, gracias a las bajas tarifas de los hoteles y la reducción impositiva de los tiquetes y cargos aeroportuarios (wEF, 2021). Los subsectores, alojamiento y restaurantes, han llegado a representar el 3.9\% en el PIB y a generar unos 110000 empleos en el país (Cotelco, 2020a).

Específicamente, la ciudad de Medellín, que fue epicentro de la violencia generada por el narcotráfico en los años noventa del siglo xx, también ha mostrado un incremento en la actividad turística en los inicios del siglo xxi. Así, durante el período 2005-2015, la participación del turismo en el PIB de la ciudad se ubicó entre el 8\% y 9\%, convirtiendo el sector en un motor de desarrollo socioeconómico (Brida et al., 2021). Según un estudio efectuado por Valencia, Vanegas, Correa y Restrepo (2017), los meses con mayor incidencia de turistas extranjeros en la ciudad son: julio y agosto, debido a la Feria de las Flores, que es un evento anual de ciudad; y diciembre, por el alumbrado navideño.

El dinamismo del sector ha generado una alta competencia, en especial para algunos negocios del subsector de alojamiento que venían presentando dificultades económicas, para cuya mitigación se proponían estrategias como la reducción de gastos y enfocar el mercadeo para incrementar la ocupación (Richard, 2017), mejorar la experiencia del cliente a través de la tecnología y la innovación (Millán \& Gómez, 2018), todo esto con el fin de mejorar su competitividad. Sin embargo, debido a la cuarentena y al aislamiento social derivados de la pandemia del Covid-19, este sector ha sido uno de los de mayor afectación (Cepal, 2020). De igual manera, la pertinencia de las políticas públicas y el plan sectorial de turismo de Colombia se vio afectada por los fuertes impactos de la pandemia en el país, por lo que se requiere el replanteamiento de sus estrategias, orientadas a la reactivación del sector turístico, y el acompañamiento al tejido empresarial (Corzo, 2021). 
La situación ha motivado publicaciones académicas en las que se proponen diversas estrategias para la recuperación del sector turístico en general y el subsector de alojamiento en particular. Así, Mendoza y Reinoso (2020) recomiendan el desarrollo de redes en turismo para generar sinergias entre los distintos operadores del sector, y que las estrategias más utilizadas para afrontar la crisis se vinculen a la atracción de nuevos clientes, el mercadeo en redes sociales, y la disminución de tarifas. Álvarez-Ferrer y Campa-Planas (2020) hacen énfasis en la importancia de superar los bajos márgenes de rentabilidad, el alto nivel de endeudamiento, la baja capacidad de autofinanciación y la escasa generación de recursos. Para Shin y Kang (2020), el principal problema por atacar es la percepción de riesgo para la salud, que va a permanecer en las personas como condicionante para viajar, por lo que se deben implementar estrategias de reducción de riesgos con el ánimo de brindar seguridad y atraer a los clientes.

De otro lado, Higgins-Desbiolles (2020) argumenta que la crisis derivada por la pandemia de Covid-19 ofrece una oportunidad única para repensar y redireccionar el turismo hacia una mejor vía en el futuro, en la cual primen los derechos, intereses y el bienestar de los stakeholders bajo un marco social y ecológico. Antes de la crisis se convivía con diversas problemáticas debido al desarrollo del turismo no planificado en diversos destinos, tales como la gentrificación turística, el cambio climático y los daños ecológicos. La tragedia global derivada de los efectos del Covid-19 puede visibilizarse como una oportunidad de transformación hacia un turismo sostenible, tendencia que ha cobrado gran relevancia durante los últimos años y que puede desarrollarse en toda la cadena de valor del sector turístico. Concretamente los hoteles pueden contribuir al cuidado del medio ambiente a través de la introducción de buenas prácticas en sus procesos, lo cual también se puede certificar mediante las normas técnicas que regulan el sector.

La premura es sobrevivir a la crisis, para lo cual los establecimientos dedicados al servicio de alojamiento están tomando medidas de diversa índole. De acuerdo con Nicola et al. (2020), cadenas hoteleras como Marriott International han otorgado licencias a decenas de miles de empleados, mientras que Hilton Worldwide acudió a la solicitud de préstamos de dinero en virtud de preservar las finanzas y flexibilidad ante la incertidumbre de los mercados. Por su parte, MGM Resorts International anunció la suspensión temporal de la operación de sus propiedades en Las Vegas, con el cierre del hotel y casino. Medidas similares y otras propias del contexto local están siendo aplicadas en Colombia y particularmente en Medellín. 


\section{Metodología}

Por tratarse de un fenómeno nuevo en el contexto actual, no solo para los negocios, sino para la sociedad en general, se decidió que la mejor forma de abordarlo para ir ganando en su comprensión es el diseño cualitativo. Este se considera el más indicado cuando se trata de constructos o conceptos poco conocidos o no suficientemente comprendidos en nuevas poblaciones o contextos, pues está fundamentado en la realidad y orientado a los descubrimientos (Cook \& Reichardt, 1986). Se trata de un proceso sistemático y riguroso, guiado por la disciplina y la teoría, siguiendo las reglas y convenciones de la investigación científica estándar (Choo et al., 2015).

Aspers y Corte (2019) definen la investigación cualitativa como "un proceso iterativo en el que se logra una mejor comprensión de la comunidad científica mediante la realización de nuevas distinciones significativas resultantes del acercamiento al fenómeno estudiado" (p. 155). Ello se complementa con la afirmación de Denzin y Lincoln (2005) en cuanto a que los investigadores cualitativos estudian las cosas en su entorno natural, intentando dar sentido a los fenómenos o interpretándolos en términos de los significados que las personas les aportan. La investigación cualitativa implica la recopilación y el análisis de una variedad de materiales empíricos que describen momentos y significados rutinarios o problemáticos en la vida de las personas o en la sociedad en general.

Así, este estudio se desarrolló con una estrategia cualitativa de naturaleza exploratoria, pues se describen los impactos y cambios que, a nivel organizacional, ha originado un fenómeno nuevo, desde la perspectiva gerencial del subsector de alojamiento, basado en fuentes y técnicas de recolección de información diversas. En primer lugar, se llevó a cabo una revisión de los portales de establecimientos especializados en la actividad turística, como la Organización Mundial del Turismo (Омт), la Asociación Hotelera y Turística de Colombia (Cotelco) y el Observatorio Turístico de Medellín (OTM), con el propósito de contextualizar las consecuencias y perspectivas gremiales por las restricciones al turismo derivadas de la declaración de confinamiento y aislamiento social. Esta información se complementó con la búsqueda de noticias en medios económicos. En ambas revisiones se usó como técnica el análisis de contenido. 
Con la meta de profundizar en la información obtenida y para conocer las vivencias, estrategias implementadas y expectativas futuras de los empresarios del sector, se establecieron contactos con directivos de hoteles seleccionados mediante un muestreo por conveniencia. Siendo la unidad de análisis el establecimiento hotelero, se incluyeron representantes tanto de los de gran formato, con centenas de habitaciones, como de los medianos y de los pequeños negocios, con decenas de cuartos.

De esta forma, se contó con la participación de funcionarios de una cadena hotelera tradicional que, con 25 hoteles, distribuidos en 11 ciudades colombianas, y una trayectoria en el mercado superior a los 50 años, es considerada líder en el país. En Medellín hace presencia con cinco unidades de negocios, con diferentes formatos que van desde el turismo de negocios hasta la oferta de servicios en apartamentos para largas estadías, con una capacidad instalada de 559 habitaciones, por lo que se considera representativa del sector formal de alojamiento. Está orientada principalmente al mercado nacional.

También se realizó una entrevista al gerente general de una cadena de tres hoteles que opera bajo el formato de apartasuites, que franquicia dos marcas internacionales y una propia, orientado al mercado extranjero. La capacidad total de esta cadena es de 194 habitaciones. Además, se contó con la participación del gerente de un hotel ubicado en el llamado Sector de la 80 en Medellín, con capacidad de hasta 80 habitaciones entre alcobas individuales y apartamentos, sus clientes son especialmente extranjeros a los que se ofrece estadías de corto y largo plazo. El gerente es además propietario y pertenece a una red de establecimientos que brindan hospedaje, ubicados, en su mayoría, en el sector Laureles-Estadio; entre todos los miembros de la red, alcanzan una capacidad de 600 habitaciones.

Adicionalmente, se entrevistó al presidente de la agremiación de pymes del turismo, organización que congrega a 1200 micro, pequeñas y medianas empresas entre hoteles, restaurantes y agentes de viaje, distribuidos en todo el país.

Finalmente, se entrevistó al gerente general de una cadena hotelera colombiana autodenominada como la de mayor recordación y confianza del país, que en la ciudad de Medellín cuenta con 3 hoteles de gran formato en el sector Milla de Oro y Castropol. Su hotel principal, categorizado en la línea de lujo y confort, es considerado como uno de los líderes de la ciudad, pues tiene una trayectoria superior a los 23 años en el mercado 
y fue el primer hotel de gran formato en reabrir sus puertas en Medellín a finales del primer semestre del año 2020, luego de realizar inversiones en tecnología para minimizar el riesgo de contagio a los huéspedes.

La técnica utilizada para la recolección de información fue la entrevista. De esta forma se logró una aproximación a la situación del sector desde los grandes hoteles pertenecientes a cadenas tradicionales del país hasta la de los microempresarios del alojamiento.

Los resultados se presentan conforme con estas categorías: diagnóstico, medidas adoptadas, estrategias de supervivencia, alternativas y perspectivas, que se muestran en apartados diferentes, en cada uno de los cuales se parte de la situación global o nacional para mostrar luego los casos específicos de los establecimientos analizados.

\section{Resultados}

\subsection{Diagnóstico}

De acuerdo con el Consejo Mundial de Viajes y Turismo (wTTC, por su sigla en inglés), la pandemia ha puesto en jaque al turismo en todos los países. La entidad que produce informes sobre el impacto económico y laboral de los viajes y el turismo revela que en el año 2020 se perdieron 62 millones de puestos de trabajo a nivel global, representando una caída del $18.5 \%$, y dejando solo 272 millones de empleados en todo el sector, en comparación con los 334 millones del año 2019. El Covid-19 paralizó el planeta durante el año 2020 y sigue devastándolo en el año 2021, dada la amenaza que representa para las empresas, los gobiernos y las comunidades. El organismo resalta la importancia de comprender y proyectar la evolución del fenómeno para la toma de decisiones estratégicas, efectivas y oportunas, con el fin de reactivar el sector de forma responsable. Para ello destaca aspectos relevantes como las alianzas estratégicas y generación de confianza con los stakeholders, la concepción de la salud e higiene como la nueva normalidad, la sostenibilidad como responsabilidad colectiva, la salud mental como aspecto vital para una vida sana y la irrupción digital a gran escala (wTTc, 2021a). 
Según el informe anual del período 2021, publicado por este organismo, se indica que, a nivel global, 1 de cada 4 nuevos empleos netos fueron generados a través de la industria de viajes y turismo durante 2014-2019. En el caso colombiano, la contribución total del sector turístico al empleo fue del 5.5\% del total de empleos en 2019, mientras que en 2020 la cifra se redujo al 4.4\%. En el año 2019 este sector contribuyó con un $10.4 \%$ al PIB mundial, cuota que se redujo al 5.5\% en el año 2020 debido a las continuas restricciones a la movilidad. Mientras que en el contexto colombiano la contribución total de viajes y turismo al PIB en el año 2019 fue del 5.0\%, cifra que disminuyó al $2.3 \%$ en el año 2020 (wTTC, 2021b).

En Colombia, la ocupación hotelera alcanzó mínimos históricos que no se habían registrado antes en el subsector. Según información de Cotelco, el $80 \%$ de los hoteles en el país cerraron al público desde la última semana de marzo de 2020 hasta el $1^{\circ}$ de septiembre del mismo año, y los que continuaron operando presentaron una ocupación promedio del 2.9\% (Cotelco, 2020a).

A fin de mitigar un poco las funestas consecuencias para el subsector, la agremiación de hoteleros presentó estas solicitudes al gobierno nacional (Cotelco, 2020a):

- Subsidio a la nómina.

- Desmonte de la sobretasa de energía.

- Créditos con tasa cero.

- Exclusión del iva para: hoteles medicalizados, compra de suministros, insumos y servicios, intermediación de agencias de viajes y arrendamientos comerciales.

- Disminución de la renta a un máximo del 10\%.

- Exoneración de la retención en la fuente.

En la figura 1, se ilustra el porcentaje de ocupación hotelera de la ciudad de Medellín. Contiene datos mensuales para los años 2019 y 2020, el comparativo permite visibilizar la fuerte caída del índice a partir del mes de marzo de 2020. 


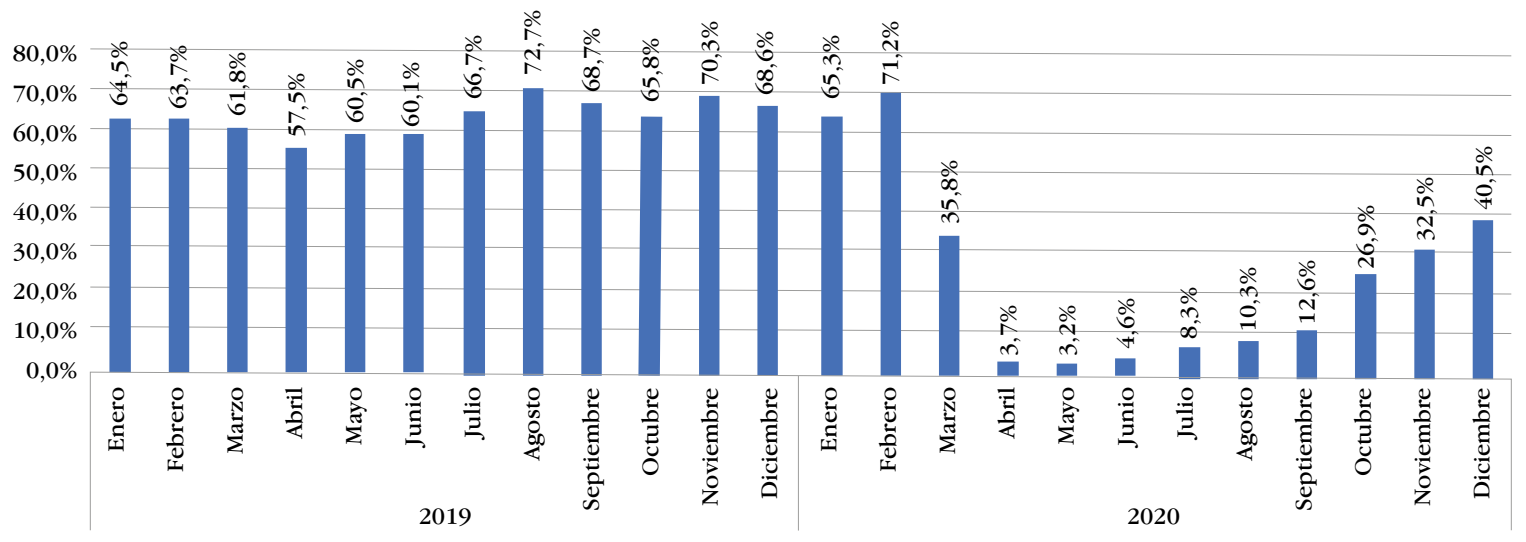

Figura 1. Porcentaje de ocupación hotelera mensual Medellín 2019-2020

Fuente: elaboración de los autores a partir de los indicadores del otm (2021a).

Mientras que el promedio anual de ocupación hotelera en Medellín en 2019 fue del 65\%, en 2020 el índice cayó, y se ubicó en un 26\% en promedio. El período de mayor afectación durante 2020 cubre los meses de abril hasta junio, una leve recuperación inicia de julio a septiembre, mes en que se permitió la reapertura gradual del sector, y se refleja un fortalecimiento del indicador en el último trimestre del año.

En la figura 2 se encuentra el mapa de Medellín que contiene la división administrativa de las 16 comunas localizadas en la zona urbana de la ciudad. Según el отм (2021a), la comuna 14: El Poblado, una de las zonas residenciales más exclusivas de la ciudad, presenta mayor ocupación hotelera, seguida de la comuna 11: Laureles-Estadio, que ocupa el segundo lugar, y en el último puesto está la comuna 10: La Candelaria, zona céntrica de Medellín. 


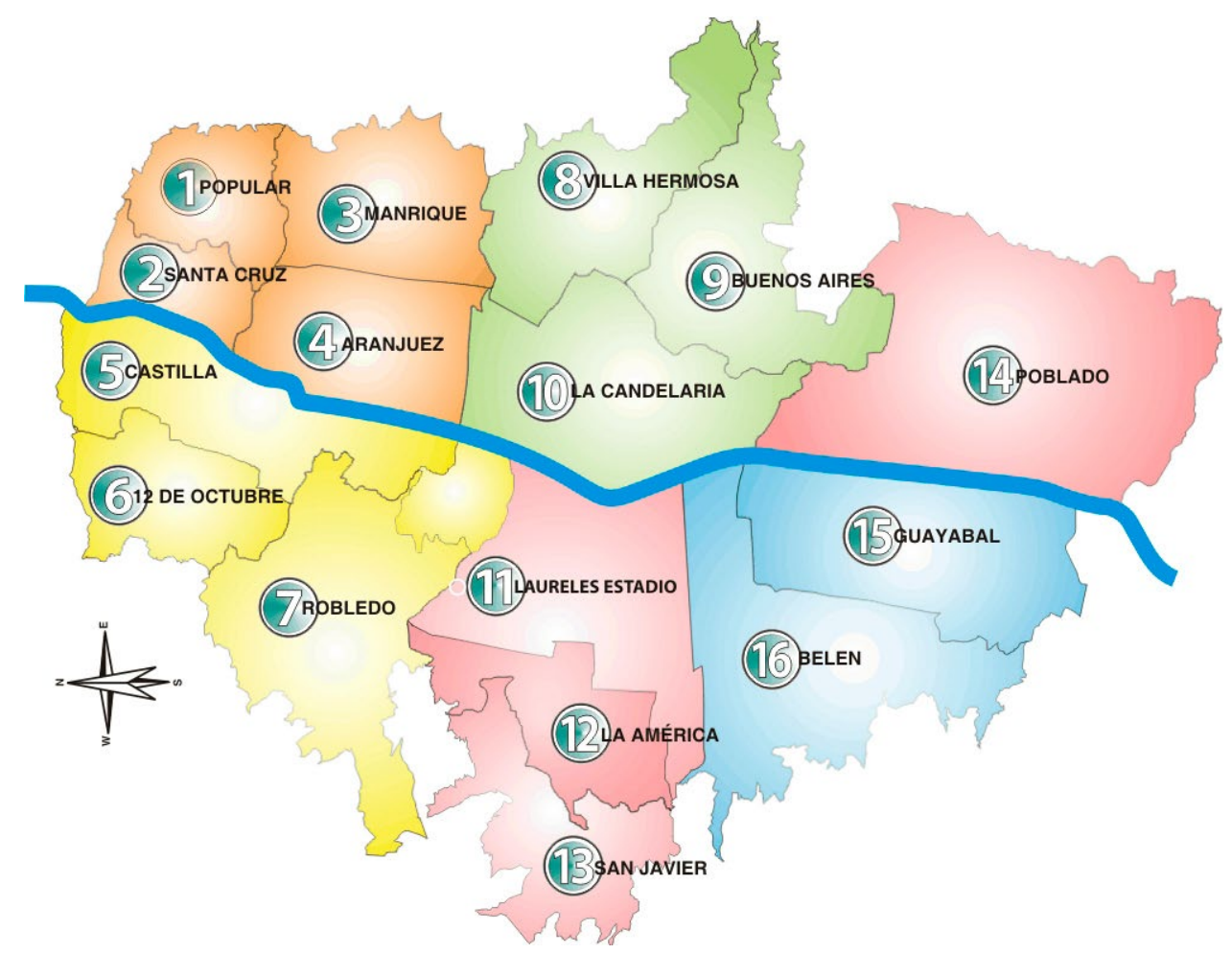

Figura 2. Mapa de comunas de Medellín

Fuente: tomada de la galería de imágenes de la Escuela del Hábitat-Cehap, Facultad de Arquitectura, Universidad Nacional de Colombia - sede Medellín (2021).

En la tabla 1, se presenta la cantidad de viajeros que ingresaron a Medellín por el Aeropuerto Internacional José María Córdova. Se compara la cantidad de personas extranjeras y nacionales que ingresaron a la ciudad en el período 2019-2010.

Tabla 1. Ingreso anual de extranjeros y nacionales Aeropuerto JMC Medellín 2019-2020

\begin{tabular}{cccc}
\hline Año & Clasificación & Total visitantes & Total general \\
\hline \multirow{2}{*}{2019} & Colombianos & 545582 & \\
\cline { 2 - 3 } & Extranjeros & 384248 & 929830 \\
\hline \multirow{2}{*}{2020} & Colombianos & 181058 & \multirow{2}{*}{305347} \\
\cline { 2 - 3 } & Extranjeros & 124289 & \\
\hline
\end{tabular}

Fuente: elaboración de los autores a partir de los indicadores del otm (2021b).

Se evidencia una drástica disminución en el arribo de pasajeros nacionales e internacionales en el año 2020, con reducciones iguales o superiores al $200 \%$, en comparación con el año 2019. En cuanto al origen de los visitantes, el $41 \%$ fueron extranjeros y el 59\%, 
colombianos. El отм indica que el ingreso de visitantes extranjeros a la ciudad de Medellín empezó a mejorar a partir del mes de septiembre de 2020, lo que coincide con la fecha de reapertura gradual del sector.

De otro lado, específicamente en los establecimientos estudiados, se encontró lo siguiente: en la cadena tradicional, de los 5 hoteles existentes en Medellín, únicamente continuaron operando 2 unidades de negocio, gracias a que en estos edificios residen algunos propietarios y normalmente se alojan huéspedes de largas estadías, y pacientes que arribaron a la ciudad por motivos de turismo de salud y que no pudieron salir del territorio antes de que se decretara el aislamiento obligatorio. Sin embargo, los porcentajes de ocupación fueron mínimos.

Esta situación coincidió con un momento de expansión de la cadena, que tuvo un incremento en los activos de propiedad, planta y equipo de casi cop 20000 millones en total, entre 2018 y 2019, representados, entre otros, en nuevos establecimientos y remodelación de los existentes. Gran parte de esta expansión se financió con obligaciones bancarias, pues el monto total de estas, en ese mismo lapso, tuvo un incremento de cop 11500 millones. Como es lógico, este endeudamiento ha hecho más difícil la situación, dado que si los ingresos no cubren los costos y gastos operacionales, menos aún los gastos financieros.

Por su parte, el propietario del hotel 'mediano' manifiesta que no está de acuerdo con esa cifra de ocupación entre el $2 \%$ y el 3\%. En su caso, por ejemplo, este indicador era del $70 \%$ en promedio, antes del aislamiento. Muchos de los huéspedes provienen de los países del norte que en períodos de invierno visitan la ciudad 'huyendo del frío', y permanecen hasta tres meses en el hotel. En el período estudiado, solo tenía dos huéspedes extranjeros, de larga estadía, uno de los cuales es un científico que investigaba sobre la pandemia. Esto representa una ocupación del $2.5 \%$, pero este no es el caso de la mayoría, de hecho, el $23 \%$ de los establecimientos de la red de hoteles Laureles-Estadio cerró definitivamente.

Conforme con el presidente de la agremiación de pymes del turismo, esta ha sido también la situación de los micro, pequeños y medianos negocios de hospedaje. Además, como se "preveía un 2020 muy bueno", y se recibieron muchas reservas anticipadas en los dos primeros meses del año con pagos adelantados, estos dineros hicieron parte del flujo de caja de los operadores, pero, al no hacerse efectivo el servicio, esos pagos se 
convirtieron en un problema, porque el dinero ya se había utilizado para cubrir diversos gastos operacionales. Afortunadamente el gobierno, a través del Decreto Legislativo 557 de 2020, reordenó el derecho de retracto, desistimiento y otras circunstancias de reembolso. En este sentido, los servicios pueden ser tomados hasta por un año más a la vigencia de la emergencia sanitaria, y así los prestadores de servicios turísticos no tienen la obligación de hacer devoluciones de efectivo.

El gerente general de la cadena hotelera colombiana con establecimiento líder en la ciudad expresa que antes de la pandemia gozaban de altos índices de ocupación hotelera, incluso por encima de la media nacional. Sin embargo, debido a la coyuntura, sus hoteles llegaron a un indicador de entre 1 a 3 habitaciones ocupadas. Teniendo en cuenta factores como la relación costo-beneficio y la complejidad de controlar la salida de los huéspedes, las juntas directivas decidieron trasladar estas personas a un hotel de la competencia y cerrar sus operaciones temporalmente al público, pues era más rentable y estratégico para la compañía.

En el caso de los hoteles de apartasuites, fue más grave la disminución en los niveles de ocupación, dado que más del 50\% de sus huéspedes proceden del extranjero, mercado más afectado debido al cierre de fronteras internacionales. Así, aunque las reservas a principios de marzo de 2020 generaron una previsión de ocupación superior al 70\%, al final del mes, esta solo alcanzó el 3\%. Y en los meses siguientes fue de prácticamente cero; además, también presenta un gran nivel de endeudamiento, que asciende actualmente a casi cop 3500 millones, debido a un proyecto de remodelación y reequipamiento de todas las suites con el fin de modernizarlas. Debido a este endeudamiento, los bancos no le concedieron más créditos.

\subsection{Medidas adoptadas por los entes gubernamentales y gremiales}

Según el Ministerio de Comercio, Industria y Turismo, se emprendieron algunas acciones para generar un alivio económico al sector productivo, relacionadas con la emisión de decretos que aplazaron las fechas de pago de impuestos y contribuciones de las empresas, ampliaron la renovación del Registro Nacional de Turismo y del Registro Mercantil, excluyeron de forma temporal el IVA a los servicios turísticos y hoteleros, aplazaron el pago de la contribución parafiscal, suspendieron temporalmente la sobretasa de energía 
al sector de alojamiento y se introdujeron líneas de créditos a través de Bancoldex y el Fondo Nacional de Garantías. En lo que respecta al mediano plazo, se diseñaron estrategias de reactivación al turismo, por medio de procesos de bioseguridad y gestión de riesgos, denominados "Check in certificado", dirigido a prestadores de servicios turísticos, que refrenda el Icontec mediante un sello de calidad. Con el fin de posicionar al país y dinamizar su flujo de turistas nacionales y extranjeros, se rediseñaron las campañas de promoción nacional e internacional, junto con un proceso de 'repriorización' de productos y mercados turísticos, una póliza para procesos de reembolso en caso de cancelaciones, entre otras acciones (Mincit, 2020a).

Los expertos coinciden en que la industria turística depende de diversos sectores subyacentes, como el de transporte, pues es un importante condicionante para que se generen flujos de visitantes. Por varios meses, el subsector de la aviación comercial literalmente no tenía a dónde volar, salvo situaciones de fuerza mayor como los vuelos de repatriación. La reactivación de los vuelos comerciales y del transporte terrestre fueron objeto de análisis por parte del gobierno nacional durante el tiempo en que se llevó a cabo el presente estudio, ya que su reapertura dependía en gran medida del comportamiento y evolución de la pandemia.

Como agremiación y considerando la importancia de la aplicación de protocolos de bioseguridad para garantizar la confianza de los clientes, Cotelco diseñó el sello "Juntos contra el Covid", dirigido a los hoteles, consistente en un programa de formación virtual sobre protocolos de bioseguridad generales y aplicados en áreas como alojamiento, alimentos y bebidas, áreas húmedas y zonas comunes. La iniciativa recogió las exigencias del Ministerio de Salud y Protección Social, y, en conjunto con una auditoría presencial, los expertos validarían el estricto cumplimiento de los estándares, para que, en el caso de detectarse alguna desviación a la norma, se diseñara un plan de acción para ajustar los respectivos procesos (Cotelco, 2020b). De esta forma se capacitó a los actores del sector de alojamiento sobre la importancia de operar de modo responsable. Así las cosas, la prioridad sería la salud y la seguridad de los empleados, clientes, proveedores y socios de servicio, asegurándose de que están cumpliendo con todas las directivas gubernamentales para ayudar a detener la propagación del virus. 
En la tabla 2 se listan las estrategias de la Alcaldía de Medellín y la Subsecretaría de Turismo para tratar de subsanar la difícil situación de los empresarios hoteleros, agencias de viajes, restaurantes y bares, considerados como los contribuyentes más afectados por las medidas tomadas para contener la pandemia.

Tabla 2. Estrategias de la Alcaldía de Medellín - Subsecretaría de Turismo para mejorar la situación del sector turismo

\begin{tabular}{|c|c|}
\hline Medidas & Alcance \\
\hline Impuestos: alivios tributarios & $\begin{array}{l}\text { - Aplazamiento del pago de los impuestos predial y de industria y comercio } \\
\text { durante el primer semestre del año 2021, a petición del contribuyente. } \\
\text { - Pago anualizado del impuesto predial con descuentos por pronto pago, } \\
\text { según calendario tributario. } \\
\text { - Ampliación de la fecha límite de pago del impuesto predial sin recargo } \\
\text { para el tercer y cuarto trimestre del año } 2021 \text {. }\end{array}$ \\
\hline Estímulos económicos & $\begin{array}{l}\text { Se destinaron cop } 800 \text { millones para apalancar la ejecución de proyectos de } \\
\text { innovación empresarial enmarcados en temáticas de competitividad, pro- } \\
\text { moción y mercadeo, para lo cual se realizó una convocatoria a stakeholders } \\
\text { del sector turístico de la ciudad. Los apoyos para cada uno los ganadores se } \\
\text { estipularon entre } 15 \text { y } 45 \text { salarios mínimos mensuales legales vigentes. }\end{array}$ \\
\hline $\begin{array}{l}\text { Encuentro de la industria del turismo } \\
\text { "Unidos por la reactivación" }\end{array}$ & $\begin{array}{l}\text { Evento en el que participaron diversos stakeholders de la cadena de valor } \\
\text { del sector turístico de Medellín y Antioquia, con el propósito de potenciar y } \\
\text { promover el turismo en la ciudad-región. Se visibilizó como una alianza estra- } \\
\text { tégica para la recuperación económica y el posicionamiento de los destinos } \\
\text { de manera articulada. }\end{array}$ \\
\hline $\begin{array}{l}\text { Medellín y Bogotá, "unidas por la } \\
\text { reactivación turística" }\end{array}$ & $\begin{array}{l}\text { Ambas ciudades firmaron memorando de entendimiento, que estará vigente } \\
\text { hasta el año } 2023 \text { y consiste en el compromiso de trabajar de forma manco- } \\
\text { munada y unir esfuerzos para la promoción de ambos destinos, apoyarse en } \\
\text { eventos y reuniones, intercambiar información relevante, identificar y replicar } \\
\text { las mejores prácticas del turismo. }\end{array}$ \\
\hline $\begin{array}{l}\text { Medellín y Ciudad de México, "uni- } \\
\text { dos por la reactivación del turismo a } \\
\text { escala internacional" }\end{array}$ & $\begin{array}{l}\text { México representa el segundo mercado en importancia y potencial de cre- } \\
\text { cimiento para el turismo de Medellín, por lo que ambas ciudades firmaron } \\
\text { memorando de entendimiento y se comprometieron a ejecutar un plan de } \\
\text { acción conjunta con el fin de reactivar el turismo en ambos destinos, que } \\
\text { estará vigente hasta el año } 2023 \text {, en virtud del cual se llevarán a cabo activi- } \\
\text { dades colaborativas de promoción para incentivar la visita de turistas. }\end{array}$ \\
\hline
\end{tabular}

Fuente: elaboración de los autores a partir de información extraída de la Alcaldía de Medellín y el Instituto Distrital de Turismo de Bogotá (2021).

\subsection{Estrategias de supervivencia}

A nivel interno, los prestadores de servicios de alojamiento y hospedaje buscaron la reducción de costos y la protección del empleo del personal de planta con estrategias como suspender los contratos de trabajo del personal temporal y anticipar las vacaciones del 
personal de planta. Algunos expertos en derecho laboral recomendaron la combinación de esta última medida con licencias no remuneradas. Factor contraproducente para el sector turístico en general, pues si a las personas les adelantan varios períodos de vacaciones y posteriormente disponen de espacio libre no remunerado, difícilmente dispondrán de los recursos, en el corto plazo, para viajar en el disfrute de estas.

La cadena tradicional, por ejemplo, con el fin de seguir posicionándose en la mente de sus consumidores y en concordancia con la campaña "Modifica, no canceles", envió invitaciones para que las personas publiquen fotografías de sus recuerdos en alguno de los hoteles, a través de sus redes sociales. Además, con la intención de generar lazos de confianza y fidelidad, informaron públicamente sobre la flexibilización de sus políticas de reservaciones y cancelaciones. También resaltaron los esfuerzos por tratar de conservar el empleo de más de 2300 colaboradores, para ello, la mayoría de los empleados de las sedes que se encontraban operando laboraron bajo la modalidad de teletrabajo, a excepción de algunos colaboradores del área operativa, en donde el contacto directo con los huéspedes es indispensable. Así mismo, entre semana, algunos empleados del área administrativa y contable visitaron las instalaciones para llevar a cabo labores de inventario, tesorería, inspección y control.

Adicionalmente, adoptaron medidas tendientes a mejorar la infraestructura de los establecimientos por medio de remodelaciones en las habitaciones, manutención de fachadas, ejecución de obras físicas y otras labores que el Departamento de Mantenimiento no podía realizar en un $100 \%$ cuando los hoteles se encontraban en alta ocupación.

Los directivos implementaron protocolos de bioseguridad con la constante desinfección de ascensores, escaleras, salas de reuniones, mobiliario en espacios comunes, manijas, teléfonos, interruptores, entre otros, la instalación de estaciones de sanitizante y tapetes con soluciones desinfectantes, y la entrega de kits de prevención a huéspedes y visitantes. Igualmente, la cadena firmó un contrato con Bureau Veritas para evaluar los protocolos de prevención frente al Covid-19, con el ánimo de recibir el sello "Check in certificado" del Ministerio de Comercio, Industria y Turismo, así como el sello "Safe Guard", que avala los hoteles en dichos protocolos a nivel internacional.

Con el ánimo de fortalecer los índices de ocupación y multiplicar sus fuentes de ingresos, los directivos diseñaron un programa denominado "Pasadía office", brindando a los 
ejecutivos la posibilidad de trabajar en un espacio seguro, cómodo y sin distracciones. La estrategia motivó a que el cliente trasladase su bome office al hotel, en una habitación exclusiva, con descuento en alimentos y bebidas, estación de café y botellas de agua, internet wi-fi, parqueadero gratis y diez impresiones por día. Adicionalmente, les obsequiaban un kit con tapabocas, gel antibacterial, paños húmedos y lapicero.

No obstante los esfuerzos por conservar el empleo de todos los trabajadores, la crisis los obligó a efectuar un recorte masivo de personal de más de 50 empleados, tanto de áreas administrativas como operativas, en el mes de junio de 2020.

El hotel mediano, que cuenta con una planta fija de 16 empleados y 4 temporales que se contratan cuando la ocupación llega al 70\%, inició el proceso enviando a sus colaboradores a vacaciones, pero, ante la imposibilidad de continuar pagando la nómina, tuvo que recurrir a la licencia no remunerada, y, posteriormente, a la terminación del contrato de la cuarta parte de su personal, aunque el gerente manifestó temor por las consecuencias que esta medida pueda ocasionar ante el Ministerio de Trabajo. También, estudiaron los protocolos de bioseguridad y las acciones de hoteles competidores de la ciudad, así como las buenas prácticas de otros países. Construyeron un protocolo interno con los empleados, que contempló el uso de mascarillas y protectores, desinfección en el ingreso al hotel, gel para lavar las manos, termómetro para medir temperatura, entre otros. Los colaboradores registran estas actividades en su sistema a través de una lista de chequeo.

La cadena hotelera colombiana con establecimiento líder en la ciudad, según decisión de sus juntas directivas, trató de preservar al máximo los contratos laborales, programando y anticipando las vacaciones al personal por varios períodos, con la autorización de cada empleado. Cancelaron todos los contratos de colaboradores en período de prueba y acordaron no renovar los contratos de término fijo. Se vieron en la obligación de realizar ajustes en la nómina para las personas que devengan salarios superiores a 1100000 pesos. La disminución se dio progresivamente de acuerdo con el salario, entre el $20 \%$ y el 50\%; este último porcentaje solo se aplicó al salario del gerente. Así mismo, cancelaron los patrocinios con el Servicio Nacional de Aprendizaje (Sena) y los contratos con terceros, para un resultado de más de 90 contratos suspendidos, congelados o cancelados. Posteriormente, hicieron un acuerdo con proveedores y acreedores para la programación de pagos parciales y futuros según la evolución de su flujo de caja. 
Su hotel principal abrió el $1^{\circ}$ de junio de 2020. De acuerdo con la Columna VIP, el gerente general del hotel presidió "el acto simbólico en el lobby principal cuando el equipo de la compañía procedió a izar las banderas, marcando en la historia del turismo el nuevo comienzo, después de este receso obligado por el Covid-19”. Para ello, además de los estrictos controles de bioseguridad, se tomaron otras medidas, como la suspensión temporal del servicio de bufet a la hora del desayuno y, "en su reemplazo, un servicio gratuito a la carta para los huéspedes en sus habitaciones”. Además, los cuatro ascensores con capacidad cada uno para quince personas operan por un sistema de comandos de voz, evitando que los huéspedes tengan que presionar botones (Columna VIP, 2020, p. 1). Lo anterior gracias al programa de domótica que adoptaron mediante la alianza con una compañía del municipio de Marinilla del departamento de Antioquia.

Según la información proporcionada por el gerente general, esta noticia impactó a todo el país, pues fueron los pioneros del sector en abrir nuevamente. Como resultado, vendieron en promedio entre 4 a 5 habitaciones por día, mientras que, en fechas especiales, como el Día del Padre, alcanzaron un tope cercano a las 25 habitaciones ocupadas. Igualmente, se dirigieron al mercado local, llegando a las personas con deseos de 'oxigenarse', algunos trabajadores cuyas familias estaban en fincas y no querían permanecer solos en sus casas, y hombres y mujeres en proceso de separación de sus parejas.

El hotel, además, lanzó una plataforma en línea para su restaurante 43 Street, el cual cuenta con servicios a domicilio. Por directriz corporativa, los colaboradores trabajaron hasta el mediodía, como estrategia para evitar la congestión en el transporte público y reducir los costos asociados a la alimentación de personal.

De los afiliados a la agremiación de pymes del turismo, muchos han cerrado sus establecimientos ante la imposibilidad de cumplir con los gastos de nómina, arrendamientos, servicios públicos, impuestos, servicio a la deuda, entre otros. Posiblemente algunos reabran con operadores diferentes y otros, dependiendo de su situación y la del mercado, decidan hacerlo directamente. 
Esta agremiación diseñó una marca de bioseguridad que pretende brindarle confianza al mercado, está entrelazada con los empresarios que decidieron participar en el proyecto. Iniciativa distinta a los protocolos que deben cumplir con el Ministerio de Salud y Protección Social. La estrategia fue plantear estándares de calidad que posteriormente sean certificados por un auditor en temas de sostenibilidad y seguridad.

En el caso de los apartasuites, se ejecutó la iniciativa del sello denominado "Clean promise", que consiste en promover las transacciones sin contacto en recepción, a través de la reducción de papeleo en los procesos de check in y check out, instalando estaciones de desinfección y tarjetas de acceso sanitarias en esta área. Introducción de nuevos estándares en los servicios de banquetes, bufet, room service, y de nuevos protocolos de lavado por medio del uso de tecnología electrostática, la reducción de mobiliario y artículos de alto contacto, que no sean indispensables, dentro de las habitaciones.

\subsection{Alternativas}

Una medida que ayudó a mitigar la difícil situación del sector de alojamiento es la campaña "Por los que nos cuidan", que consiste en hacer uso de la infraestructura hotelera ubicada cerca de los centros hospitalarios en los que se presta atención asociada al Covid-19 para que el personal médico descanse mientras estén entre turno y turno, y disfrute de servicios como alimentación y lavandería. La respuesta no se hizo esperar y el sector hotelero puso a disposición más de 8000 habitaciones (Mercado, 2020, p. 1).

Según los funcionarios de la cadena tradicional, en sus establecimientos de Medellín, durante el desarrollo del estudio, no hubo personal médico alojado. Sin embargo, se les informó que, a partir del mes de marzo de 2020, la Secretaría de Desarrollo Económico de la Alcaldía de Medellín adelantó la formulación de un proyecto para que los establecimientos de hospedaje se vincularan a satisfacer las necesidades de alojamiento de la demanda del sector salud que atiende la emergencia derivada del Covid-19, este escenario solo se haría realidad cuando la ciudad lo llegara a requerir, en función de la evolución del fenómeno.

Este programa se extendió a "Camas solidarias", abriendo la posibilidad de albergar a adultos mayores en situación de vulnerabilidad o a personas que llegaban del exterior, quienes debían cumplir con el aislamiento obligatorio y que las administradoras de riesgos 
laborales (ARL) tuvieran que garantizar la cuarentena. El gerente-propietario del hotel mediano fue contactado por la Subsecretaría de Turismo, a la que se informó sobre los inventarios disponibles. No obstante, ante la llegada de los dos huéspedes extranjeros y con el fin de brindar seguridad a clientes internos y externos, informaron a la Subsecretaría que ya no podrían recibir personas con riesgo de estar contagiados.

El gerente general de la cadena hotelera colombiana con establecimiento líder en la ciudad afirma que fueron diversas las entidades del sector público y privado que los contactaron para recolectar la información sobre los inventarios de los hoteles. Sin embargo, desistieron de participar en este proyecto, pues la tarifa es demasiado baja y resulta poco atractiva para los establecimientos de gran formato de El Poblado, por lo que les sugirieron dirigirse hacia la oferta de alojamiento del centro de Medellín.

Algunos hoteles también sirvieron como sitios para que pacientes contagiados cumplieran con la cuarentena. Aproximadamente 640 trabajadores del proyecto Hidroituango, que resultaron positivos en las pruebas del Covid-19, se alojaron en hoteles del sector Laureles-Estadio. Es de anotar que esta medida generó preocupación en los vecinos del sector, pues consideraron que no hubo suficiente control sobre la circulación de las personas contagiadas (Arbeláez, 2020). Según información proporcionada por el director de Desarrollo del Proyecto Ituango de Empresas Públicas de Medellín, los hoteles que participaron en la coyuntura fueron tres, localizados en la ciudad de Medellín y sus alrededores, donde se alojaron los 640 trabajadores, entre los que se incluyen los que han sido programados por salida de obra a descanso. En promedio, la estadía de los trabajadores en el hotel fue de nueve días, no obstante, para los casos positivos a Covid-19, el tiempo de permanencia depende de la gravedad y el proceso de recuperación de cada trabajador.

\subsection{Perspectivas para el mediano y largo plazo}

Los flujos de huéspedes del sector hotelero dependen en gran medida del turismo de reuniones, eventos y negocios que se celebren en Medellín. En la actualidad, con el auge de la tecnología y el desarrollo de actividades como el teletrabajo y la educación virtual, cobran fuerza tendencias como la ejecución de eventos híbridos, que pueden verse como una estrategia para afrontar el confinamiento forzado y una oportunidad para evolucionar la industria de los eventos en términos de alcance y cobertura, pues limitaciones físicas 
o geográficas no serían una barrera. Autores como Ranasinghe et al. (2020) apuntan que los eventos virtuales e híbridos emergen como dos opciones disruptivas, formatos que probablemente son la mejor alternativa para el turismo MICE en tiempos difíciles. Estos eventos incluyen una combinación de componentes en vivo y virtuales. En este modelo, varias personas pueden estar presentes en una ubicación física mientras la audiencia en general asiste al encuentro de forma remota. Sin embargo, también se visibiliza como una amenaza, ya que la incorporación de tecnologías y herramientas digitales mejoran la conectividad y reducen los desplazamientos de las personas, lo que supone una disminución en los gastos de viaje y, por ende, en las necesidades de transporte y alojamiento.

Por otro lado, es imperativo pensar que los hoteles deben trascender de su retórica sobre la prestación de un servicio ultralujoso al de un servicio ultrahigiénico. Actualmente, las acciones de mercadeo relacionadas con los descuentos, programas de fidelidad y las noches de cortesía ya no son suficientes para atraer y retener clientes, puesto que se deben diseñar estrategias para que las habitaciones estén libres de Covid-19 y así se transmita confianza a los clientes (Jain, 2020). Por lo tanto, hacia el futuro próximo, lo más urgente para los establecimientos hoteleros es generar confianza a los clientes potenciales ejecutando acciones como capacitación de empleados para reforzar las soluciones de limpieza y el uso de equipos de protección personal, esterilización de llaves de habitaciones, priorización de los procesos de room service para evitar aglomeraciones en las zonas de alimentación y restricción de los horarios de los servicios. Algunos expertos en seguridad y salud en el trabajo han recomendado, además, la aspersión de sales de amonio cuaternario en zonas públicas sobre superficies inanimadas cuando no haya afluencia de público; y, con fines de desinfección de los calzados, sugieren la instalación de tapetes abrasivos y pediluvios al ingreso de los hoteles, restaurantes y zonas comunes, así como el uso de soluciones de hipoclorito para limpieza de pisos y superficies que no sean atacadas por la corrosión. De esta forma sería más fácil persuadir a los clientes para evitar las cancelaciones y reprogramar sus alojamientos y eventos (Bagnera \& Stewart, 2020).

Los entrevistados coinciden en que hay mucha incertidumbre. Hay un escenario positivo, que consiste en que después de salir del aislamiento y ante la posibilidad de que una situación así pudiera presentarse nuevamente, las personas quieran vivir más intensamente, conocer y disfrutar de paisajes nuevos, cultura y gastronomía, esto posiblemente se genere inicialmente a nivel regional y nacional. El escenario negativo es que 
las posibilidades económicas y el temor al contagio lleven a una fuerte disminución en el turismo, en relación con el buen comportamiento de los indicadores económicos con los que gozaba el sector antes de la pandemia.

\section{Discusión}

Indudablemente, los directivos de muchos negocios, en especial pertenecientes al sector turístico en general y al subsector hotelero en particular, se están enfrentando quizás al mayor reto, desde el punto de vista organizacional, de sus vidas, para garantizar no solo la supervivencia de las empresas a su cargo, sino para tratar de conservar el empleo del mayor número de colaboradores posible. Como lo han dicho algunos medios de comunicación, se trata de un hecho sin precedentes en por lo menos los últimos cien años. La pandemia del Covid-19 puede considerarse un megadesastre en términos de gestión estratégica tanto por el impacto como por el alcance mundial. En retos tan grandes se ponen a prueba todos los enfoques teóricos, de los cuales ninguno fue desarrollado en un contexto similar. La ventaja, si puede considerarse como tal, es que, dadas las dimensiones y el alcance de la situación, se ha contado con el respaldo de gremios y entidades gubernamentales, que han contribuido con un diagnóstico muy amplio y medidas de mitigación del impacto.

Sin embargo, es posible asociar algunas de las medidas adoptadas por los directores del subsector de alojamiento a los enfoques presentados por los académicos. Es así que, desde el punto de vista de la gestión estratégica, una gran parte de las acciones emprendidas se enmarca dentro de la teoría de los stakebolders (Freeman \& McVea, 2001), destacando la preocupación por conservar el empleo de los colaboradores, por encima, en muchos casos, de los intereses de los propietarios. Aunque se sacrificó en todos los casos al personal temporal, la preocupación por el personal de planta llevó incluso al castigo del flujo de caja, lo cual es una decisión difícil en un momento de reducción casi total de ingresos.

Obviamente el otro grupo al que se han enfocado las estrategias es el de los clientes. A partir del reconocimiento de que la principal necesidad es su protección ante el riesgo de contagio, las medidas de bioseguridad se han impuesto sobre la oferta de bienestar. 
La renegociación con los proveedores y acreedores, resaltada por el gerente de la cadena hotelera colombiana con establecimiento líder en la ciudad, también se incluye dentro de este punto de vista.

En las estrategias adoptadas por estos directivos, igualmente se encuentran la optimización de costos y gastos, así como la decisión de concentrar los clientes en un solo establecimiento, permitiendo el cierre de los otros, con el consecuente ahorro de costos y gastos variables.

En casos como el de la cadena hotelera colombiana con establecimiento líder en la ciudad, adicional a este enfoque, hay una clara demostración de la importancia de la percepción del director, basándose en su estrategia de atraer al hotel miembros de familias en situación de soledad, especialmente en los casos de parejas separadas. Así mismo, se pueden incluir en este enfoque las campañas de publicación de fotografías que despiertan buenos recuerdos en las personas, lo que puede ayudar como terapia en contra de la depresión que genera el encierro. En forma similar, el programa "Pasadía office" ofrece una solución novedosa a una necesidad muy propia de la misma situación que generó la crisis. Y, aunque no fue una medida individual, la campaña "Por los que nos cuidan" también se enmarca dentro de esta categoría, al igual que la opción de servir como sitio para cumplir la cuarentena.

No obstante todos los esfuerzos por la supervivencia, también se tomaron medidas más drásticas, como el cierre de establecimientos.

\section{Conclusiones}

Los efectos causados por la pandemia del Covid-19 y sus variantes han transformado el estilo de vida de las personas y las rutinas organizacionales en las empresas, especialmente de servicios como el transporte, alojamiento y alimentación. Los directivos de estas se han visto obligados a diseñar y aplicar estrategias emergentes, tratando a la vez de garantizar la supervivencia de la empresa y la conservación del empleo, en una situación 
de disminución drástica de los ingresos. Una gran parte de las acciones emprendidas comprende cambios en sus procesos organizacionales, incluyendo la adaptación a las nuevas directrices y políticas gubernamentales en cuanto a la adopción de protocolos de seguridad para empleados y clientes. Y es que recuperar la confianza de los consumidores será el principal reto que el gobierno, los gremios y los directivos hoteleros deberán afrontar, pues la posibilidad de que la compra genere recompra se condicionará a que los establecimientos transmitan una imagen de seguridad y a que los clientes tengan una percepción favorable sobre la calidad y las medidas de protección en todas las fases de prestación del servicio.

En este sentido, la pandemia precipitó los cambios tecnológicos en la industria de la hospitalidad, y, con el ánimo de reducir la interacción humana y los riesgos asociados a la salud, algunos establecimientos han automatizado procesos que antes requerían de alto contacto con los huéspedes. No obstante, el común denominador, dentro del subsector de alojamiento, versa sobre la implementación de estrategias de reducción de costos, así como renegociación con proveedores y acreedores financieros, y la dilatación y reducción de impuestos. Para este subsector, se vislumbra un proceso de recuperación lento y el panorama es poco alentador, dado que se prevé un recrudecimiento en la guerra de tarifas por la alta capacidad instalada de la oferta de hospedaje y la tímida recuperación de la demanda. De todas formas, será el comportamiento del consumidor el que marque la pauta, y esta puede estar entre el miedo al contagio y los deseos de aprovechar y disfrutar al máximo la vida, en lo cual los viajes suelen estar entre las actividades de esparcimiento predilectas.

Se puede observar que los directivos entrevistados han estado a la altura de sus cargos, generando estrategias innovadoras y llegando a medidas como la disminución de sus salarios en procura de la supervivencia de los establecimientos que dirigen y la conservación del empleo. Es un desafío para los académicos de las disciplinas organizacionales sistematizar estas experiencias de tal forma que se puedan robustecer los planteamientos teóricos sobre la gestión estratégica y contribuyan, entre otros, a orientar a los directivos en situaciones imprevistas.

Las principales limitaciones del estudio se relacionan con la dispersión de la información en prensa y la imposibilidad de visitar físicamente los establecimientos hoteleros debido 
a la pandemia. En futuras investigaciones se recomienda recolectar información en otras ciudades de Colombia, así como de otros países, integrando la evolución y tendencias en el comportamiento de la oferta y la demanda, con el fin de comparar experiencias que puedan ofrecer soluciones prácticas a los directivos del sector hotelero.

\section{Referencias}

(2020). Reapertura del Hotel Dann Carlton Medellín. Columna VIP. Recuperado de https:// columnavip.com/2020/06/1000am-reapertura-del-hotel-dann-carlton-medellin/

Alberca, P., \& Parte, L. (2013). Evaluación de la eficiencia y la productividad en el sector hotelero español: un análisis regional. Investigaciones Europeas de Dirección y Economía de la Empresa, 19(2), 102-111. https://doi.org/10.1016/j.iedee.2012.10.004

Alcaldía de Medellín. (2021a). Con estímulos económicos, Medellín promueve la reactivación y recuperación del sector turístico. Recuperado de https://www.medellin.gov.co/irj/portal/ medellin?NavigationTarget=contenido/10079-Con-estimulos-economicos-Medellin-promueve-la-reactivacion-y-recuperacion-del-sector-turistico

Alcaldía de Medellín. (2021b). Cumbre del turismo cerró con acuerdo de voluntades entre Medellín y Antioquia. Recuperado de https://www.medellin.gov.co/irj/portal/medellin?NavigationTarget=contenido/10270-Cumbre-del-turismo-cerro-con-acuerdo-de-voluntades-entre-Medellin-y-Antioquia

Alcaldía de Medellín. (2021c). La Alcaldía de Medellín anuncia alivios tributarios para sectores económicos más afectados por la pandemia. Recuperado de https://www.medellin.gov. $\mathrm{co} / \mathrm{irj} / \mathrm{portal} / \mathrm{medellin?NavigationTarget=contenido/8694-La-Alcaldia-de-Medellin-anun-}$ cia-alivios-tributarios-para-sectores-economicos-mas-afectados-por-la-pandemia

Alcaldía de Medellín. (2021d). Medellín y Ciudad de México se unen por la reactivación del turismo a escala internacional. Recuperado de https://www.medellin.gov.co/irj/por$\mathrm{tal} /$ medellin?NavigationTarget=contenido/10573-Medellin-y-Ciudad-de-Mexico-se-unen-por-la-reactivacion-del-turismo-a-escala-internacional

Álvarez-Ferrer, A., \& Campa-Planas, F. (2020). La predicción del fracaso empresarial en el sector hotelero. Cuadernos de Turismo, (45), 33-59. https://doi.org/10.6018/turismo.426031

Ansell, C. (2017). Governance in turbulent times: turbulence, adaptation, and change. Oxford: Oxford University Press.

Ansoff, I., Kipley, D., Lewis, A. O., Helm-Stevens, R., \& Ansoff, R. (2018). Implanting strategic management. Cham, Switzerland: Springer. 
Arbeláez, M. (2020). Piden mayores controles a hospedajes de trabajadores de Hidroituango contagiados. RCN Radio. Recuperado de https://www.rcnradio.com/colombia/antioquia/ piden-mayores-controles-hospedajes-de-trabajadores-de-hidroituango-contagiados

Aspers, P., \& Corte, U. (2019). What is qualitative in qualitative research. Qual Sociol., 42, 139160. https://doi.org/10.1007/s11133-019-9413-7

Azócar, G. (2017). Estrategias de manejo de crisis sociales por medio de políticas públicas: mitigación y reforma. Economía y Política, 4(1), 97-124.

Bagnera, S. M., \& Stewart, E. (2020). Navigating hotel operations in times of Covid-19. Boston Hospitality Review.

Benavides, G. F. (2015). Las políticas públicas del turismo receptivo colombiano. Suma de Negocios, 6(13), 66-73.

Bourletidis, K., \& Triantafyllopoulos, Y. (2014). sMEs survival in time of crisis: strategies, tactics and commercial success stories. Procedia - Social and Behavioral Sciences, 148, 639-644.

Brida, J. G., Brindis, M. A. R., \& Mejía-Alzate, M. L. (2021). La contribución del turismo al crecimiento económico de la ciudad de Medellín-Colombia. Revista de Economía del Rosario, 24(1), 1-23.

Catalano, B. (2019). Movilidad turística e integración: teoría y métodos para su abordaje. Quid 16: Revista del Área de Estudios Urbanos, (11), 259-280.

Cepal. (2020). Dimensionar los efectos del Covid-19para pensar en la reactivación. Recuperado de https://repositorio.cepal.org/bitstream/handle/11362/45445/S2000286_es.pdf?sequence $=4 \&$ isAllowed $=\mathrm{y}$

Cook, T. D., \& Reichardt, C. S. (1986). Métodos cualitativos y cuantitativos en investigación evaluativa. Madrid: Ediciones Morata S. L.

Corzo, D. (2021). Análisis de políticas públicas. El caso del Plan Sectorial de Turismo de Colombia 2018-2022. Gran Tour, Revista de Investigaciones Turísticas, (23), 283-302.

Cotelco. (2020a). Centro de información. Recuperado de https://www.cotelcoantioquia.org/ centro-de-informacion

Cotelco. (2020b). Presentación sello Cotelco "Juntos contra el Covid". Recuperado de https:// www.cotelco.org/noticias/SelloCotelco

Choo, E. K., Garro, A. C., Ranney, M. L., Meisel, Z. F., \& Morrow Guthrie, K. (2015). Qualitative research in emergency care part I: research principles and common applications. Acad. Emerg. Med., 22, 1096-1102. https://doi.org/10.1111/acem.12736 
De Villa, M. A., \& Rajwani, T. (2013). The mirror trap: do managerial perceptions influence organizational responses to crises? Academia. Revista Latinoamericana de Estrategia, 26(1), 170-188.

Denzin, N. K., \& Lincoln, Y. S. (2005). Introduction. The discipline and practice of qualitative research. In N. K. Denzin \& Y. S. Lincoln (Eds.), The SAGE handbook of qualitative research (pp. 1-32). Thousand Oaks: sage Publications.

Duque, J. L. S. (2014). Los procesos de cambio organizacional y la generación de valor. Estudios Gerenciales, 30(131), 162-171. https://doi.org/10.1016/j.estger.2014.04.005

Freeman, R. E., \& McVea, J. A. (2001). Stakeholder approach to strategic management. Available from https://ssrn.com/abstract=263511 or http://dx.doi.org/10.2139/ssrn.263511

Gil, S. M., \& Korstanje, M. E. (2020). El turismo como objeto de investigación. Tourism as an object of study. Rosa dos Ventos-Turismo e Hospitalidade, 12(1). http://dx.doi. org/10.18226/21789061.v12i1p81

Gössling, S., Scott, D., \& Hall, C. M. (2020). Pandemics, tourism and global change: a rapid assessment of Covid-19. Journal of Sustainable Tourism, 1-20. https://doi.org/10.1080/0 9669582.2020 .1758708

Groh, M. (2014). Strategic management in times of crisis. Journal of Economics and Business Administration, 6(2), 49-57.

Higgins-Desbiolles, F. (2020). Socialising tourism for social and ecological justice after Covid-19. Tourism Geographies, 1-14. https://doi.org/10.1080/14616688.2020.1757748

Hill, C. W., \& Jones., G. R. (2009). Essentials of strategic management. Mason, usA: South Western.

Instituto Distrital de Turismo. (2021). Bogotá y Medellín firman alianza para la reactivación progresiva del sector turismo. Recuperado de https://www.idt.gov.co/es/bogota-y-medellin-firman-alianza-para-la-reactivacion-progresiva-del-sector-turismo

Jafari, J. (2005). El turismo como disciplina científica. Política y Sociedad, 42(1), 39-56.

Jain, D. (2020). Would hotel industry have to redo the rooms/housekeeping standards post Covid? Instilling Greater Confidence to Bring Back the Customers. SSRN.

Karam, M. G. (2018). The impact of strategic planning on crisis management styles in the 5-star hotels. Journal of Hotel Business Manage, 7. https://doi.org/171.10.4172/2169$0286.1000171_{-}$

Kotler, P., \& Caslione, J. A. (2009). The business of managing and marketing in the age of turbulence. New York, NY: Amacom.

Lynch, R. (2018). Strategic management. Harlow: Pearson Education. 
Menchero, M. (2018). Colombia en posconflicto: ¿turismo para la paz o paz para el turismo? Revista Iberoamericana de Filosofía, Política y Humanidades, 20(39), 415-438. https:// doi.org/10.12795/araucaria.2018.i39.20

Mendoza, Á. G. F., \& Reinoso, N. G. (2020). Estudio de pérdidas y estrategias de reactivación para el sector turístico por crisis sanitaria Covid-19 en el destino Manta (Ecuador). Revista Internacional de Turismo y Empresa. Riturem, 4(1), 79-103.

Mercado, L. (16 de abril de 2020). Hoteles le darán alojamiento y alimentación al personal médico. El Tiempo. Recuperado de https://www.eltiempo.com/politica/gobierno/hoteles-le-daran-alojamiento-y-alimentacion-al-personal-medico-485066

Millán García, C. H., \& Gómez Díaz, M. R. (2018). Factores e indicadores de competitividad hotelera. Compendium, 21(40).

Ministerio de Comercio, Industria y Turismo. (2020a). Mincit al día con las noticias más recientes del turismo. Recuperado de https://www.mincit.gov.co/prensa/noticias/turismo_

Ministerio de Comercio, Industria y Turismo. (2020b). Política de turismo sostenible "Unidos por la naturaleza”. Bogotá. Recuperado de https://www.mincit.gov.co/minturismo/calidad-y-desarrollo-sostenible/politicas-del-sector-turismo/politica-de-turismo-sostenible/ politica-de-turismo-sostenible-9.aspx

Ministerio de Comercio, Industria y Turismo. (2021). Plan Sectorial de Turismo 2018-2022. Recuperado de https://www.mincit.gov.co/minturismo/calidad-y-desarrollo-sostenible/desarrollo-regional/plan-sectorial-de-turismo-2018-2022/plan-sectorial-de-turismo-2018-2022

Nag, R., Hambrick, D. C., \& Chen, M. J. (2007). What is strategic management, really? Inductive derivation of a consensus definition of the field. Strategic Management Journal, 28(9), 935-955.

Nicola, M., Alsafi, Z., Sohrabi, C., Kerwan, A., Al-Jabir, A., ... \& Agha, R. (2020). The socio-economic implications of the coronavirus and Covid-19 pandemic: a review. International Journal of Surgery. https://doi.org/10.1016/j.ijsu.2020.04.018

Observatorio Turístico de Medellín. (2021a). Alojamiento. Recuperado de https://www.turismomed.org/observatorios/observatorio-de-alojamiento

Observatorio Turístico de Medellín. (2021b). Vuelos. Recuperado de https://www.turismomed. org/observatorios/vuelos/observatorio-de-vuelos

Organización Mundial del Turismo. (2019). Panorama del turismo internacional, edición 2019. Recuperado de https://www.e-unwto.org/doi/pdf/10.18111/9789284421237 o https://doi.org/10.18111/9789284421237 
Organización Mundial del Turismo. (2020a). Evaluación del impacto del brote de Covid-19 en el turismo internacional. Recuperado de https://www.unwto.org/es/evaluacion-de-la-incidencia-del-brote-del-covid-19-en-el-turismo-internacional

Organización Mundial del Turismo. (2020b). Glosario de términos de turismo. Recuperado de https://www.unwto.org/es/glosario-terminos-turisticos

Ranasinghe, R., Damunupola, A., Wijesundara, S., Karunarathna, C., Nawarathna, D., ... Idroos, A. A. (2020). Tourism after corona: impacts of Covid 19 pandemic and way forward for tourism, hotel and mice industry in Sri Lanka. Hotel and Mice Industry in Sri Lanka. SSRN. https://doi.org/10.13140/RG.2.2.27955.17442

Richard, B. (2017). Hotel chains: survival strategies for a dynamic future. Journal of Tourism Futures, 3(1), 56-65. https://doi.org/10.1108/JTF-06-2016-0018

Rivera Rodríguez, H. A. (2019). Turbulencia empresarial: lecciones aprendidas. Bogotá: Universidad del Rosario.

Shin, H., \& Kang, J. (2020). Reducing perceived health risk to attract hotel customers in the Covid-19 pandemic era: focused on technology innovation for social distancing and cleanliness. International Journal of Hospitality Management, 91, 102664. https://doi. org/10.1016/j.ijhm.2020.102664

Universidad Nacional de Colombia. (2021). Mapa de comunas de Medellín. Recuperado de https://arquitectura.medellin.unal.edu.co/escuelas/habitat/galeria/displayimage. php?pid=6048\&fullsize $=1$

Valencia, M., Vanegas, J., Correa, J., \& Restrepo, J. (2017). Comparación de pronósticos para la dinámica del turismo en Medellín, Colombia. Lecturas de Economía, 86, 199-230. http:// dx.doi.org/10.17533/udea.le.n86a08

Wang, W. (2009). Knowledge management adoption in times of crisis. Industrial Management E Data Systems, 109(4), 445-462.

Wolf, C., \& Floyd, S. W. (2013). Strategic planning research: toward a theory-driven agenda. Journal of Management, 43(6), 1754-1788. https://doi.org/10.1177/0149206313478185_

World Economic Forum. (2021). The travel \& tourism competitiveness report 2019. Available from http://www3.weforum.org/docs/WEF_TTCR_2019.pdf

World Travel \& Tourism Council. (2021a). Covid-19Hub. Lessons learnt. Available from https:// wttc.org/Covid-19\#Lessons\%20Learnt

World Travel \& Tourism Council. (2021b). Economic impact reports. Available from https:// wttc.org/Research/Economic-Impact 